\title{
Multi-objective optimization approach for cost management during product design at the conceptual phase
}

\author{
K. G. Durga Prasad · K. Venkata Subbaiah • \\ K. Narayana Rao
}

Received: 6 August 2012/ Accepted: 13 February 2014/Published online: 11 March 2014

(C) The Author(s) 2014. This article is published with open access at Springerlink.com

\begin{abstract}
The effective cost management during the conceptual design phase of a product is essential to develop a product with minimum cost and desired quality. The integration of the methodologies of quality function deployment (QFD), value engineering (VE) and target costing (TC) could be applied to the continuous improvement of any product during product development. To optimize customer satisfaction and total cost of a product, a mathematical model is established in this paper. This model integrates QFD, VE and TC under multi-objective optimization frame work. A case study on domestic refrigerator is presented to show the performance of the proposed model. Goal programming is adopted to attain the goals of maximum customer satisfaction and minimum cost of the product.
\end{abstract}

Keywords Product design - Cost management - Quality function deployment - Value engineering - Target costing · Multi-objective optimization · Goal programming

\section{K. G. Durga Prasad ( $\square)$}

Department of Mechanical Engineering, School of Engineering,

G.V.P. Technical Campus, Gayatri Vidya Parishad College for

Degree and P.G. Courses, Vishakhapatnam, India

e-mail: dr.kgdp@gmail.com

K. Venkata Subbaiah

Department of Mechanical Engineering, Andhra University,

Vishakhapatnam, India

e-mail: drkvsau@yahoo.co.in

K. Narayana Rao

Department of Mechanical Engineering, Govt. Polytechnic, Paderu, India

e-mail: nr_kandukuri@redifmail.com

\section{Introduction}

The cost and customer perceived quality of a product are the two faces of a coin. In the current market scenario, it is essential to develop a product at minimum cost and quality as desired by the customer. Product design and development is a techno-economic process, hence there is always a trade-off between design goals and cost constraints (Sharma 2012). Decisions made during the design phase have a significant influence on development and life cycle costs. It is generally known that $\sim 80 \%$ of the manufacturing cost of a product is determined by the design of the product (Ernst and Kamarad 2000). The product designers have to balance cost, quality and functionality in their designs to develop a product with minimum cost and greater customer satisfaction. To achieve this, it is required to manage product costs throughout the design stage. Target costing is a widely used technique for cost management during product development (Dekker and Smidt 2003; Filomena et al. 2009). It is a proactive cost management tool, which requires continuous market research where price considerations and trend changes are closely monitored to understand the perceived quality and functionality of target customers as well as the price they are willing to pay for demanded features. It is also a strategic management tool involving other managerial tools and techniques namely quality function deployment (QFD) and value engineering (VE). Cost management techniques cannot be implemented successfully without the support of QFD and VE analysis (Zengin and Ada 2010). As VE allows the identification of where cost reduction could be achieved and the TC shows the target to be achieved to assure the longterm profitability plan of a company, VE and TC are complementary processes (Ibusuki and Kaminski 2007).

A mechanical design process is generally divided into conceptual, configuration and detailed design phases. The 
main objective of conceptual design is to develop concepts to meet design specifications (Zeng and Gu 1999). This paper aims to design a product at the conceptual phase that compromises customer satisfaction and cost. A multi-objective optimization frame work is established to design a product by integrating QFD, VE and TC. It is observed from the literature that the earlier researchers focused on designing a product by integrating VE and TC in the first phase of QFD. But, there is a scope to alter the parts characteristics of a product in response to customer needs in the second phase of QFD. The second phase of QFD called Part Planning Matrix (PPM), which is the best choice for applying VE to obtain different levels of the part characteristics and then it is suitable to implement target costing approach (Jariri and Zegordi 2008a). Therefore, in this work PPM of QFD is considered for product design. Jariri and Zegordi (2008b) established a mathematical model by considering single-objective optimization approach which incorporates the first phase of QFD called house of quality (HOQ) and TC into a single model.

In this paper, a mathematical model is developed on the basis of QFD, VE and TC integration for effective cost management during the conceptual phase of product design. The model is solved under multi-objective optimization to obtain trade-off between customer satisfaction and cost of the product. In the multi-objective decision-making problems, the objectives may be competitive among themselves. Unlike a unique optimal solution in the case of single-objective decision making, the decision maker can get efficient or nondominated solution in the case of multi-objective decisionmaking problems. Goal programming (GP) is the most useful multi-objective technique (Gosh and Roy 2013). In the present work, GP technique is employed for multi-objective optimization with a view to optimize customer satisfaction index and total cost of the product simultaneously. The conceptual phase of designing a domestic refrigerator is considered to illustrate the proposed methodology.

The rest of the paper is organized as follows. The literature related to the techniques QFD, VE and TC is briefly reviewed in the "Literature review". In "Methodology", proposed methodology is presented. The application of the proposed methodology is described in "Illustrative example" with an illustrative example by considering conceptual design of a domestic refrigerator. The results and discussions are made in "Results and discussion". Finally, conclusions are discussed in "Conclusions".

\section{Literature review}

\section{Quality function deployment}

Quality function deployment is a customer-oriented design technique, which was conceptualized in the late 1960s. It has been adopted in various industries with a view to add quality, value and customer satisfaction during the design and development of new products and services. QFD is a four-phase structured methodology to translate the customer needs into design requirements, and subsequently into parts characteristics, process plans, and production requirements associated with its manufacture (Hassan et al. 2009). It consists of a series of correspondence matrices which are sequenced to reflect a typical path in the product development process such that outputs of a matrix are inputs in a succeeding matrix (Fogliatto et al. 2003). Product planning matrix is the first matrix, which is known as HOQ and it maps prioritized list of customer needs to appropriate design requirements. The outcome of HOQ analysis is the list of priority ratings of the design requirements. The second matrix of QFD approach is the assembly/parts planning matrix which maps the prioritized design requirements to critical parts characteristics. The other matrices are process planning matrix and production planning matrix.

Most of the QFD studies focused on enhancing customer satisfaction by increasing the functionality of the product. The financial factor was almost neglected in the earlier QFD applications (Tang et al. 2002). But in the present difficult economic times, it is necessary to integrate cost deployment into QFD (Ross and Mazur 2009). The objective of cost deployment is to achieve the target cost while keeping a balance with quality (Jiang et al. 2007). Bode and Fung (1998) integrates design costs into the QFD frame work, which facilitates the designers to optimize product development resources towards customer satisfaction. Eversheim et al. (1998) presented a methodology to integrate cost modeling and QFD for making trade-off decisions between quality and cost at the early stages of product design. Tsai and Chang (2004) developed a method of quick cost estimation based on function characteristics and the QFD technique. Iranmanesh et al. (2005) presented an integrated approach to optimize cost while respecting the customer perception of a product using a modified QFD method. Takai and Ishii (2006) proposed a method of decomposition of QFD matrices simultaneously for both requirements and structure to allocate the worth and target cost of the modules in a system.

\section{Value engineering}

Value engineering is a systematic and function-based approach to improve the value of products. The purpose of $\mathrm{VE}$ is to attain the desired function at minimum cost. It is an organized creative technique directed at analyzing the functions of a product with the purpose of achieving the required functions at the lowest overall cost constituent with all the requirements, which comprise its value. VE is a 
process in which a product is analyzed in terms of the functions performed by the product. Costs associated with these functions, and disparity of value, in terms of the cost to importance of the functions are identified and targeted for improvement (Mendoza et al. 2003). This approach can be termed as functional cost analysis in which weightages for the functions of each part can be compared with the relative costs of the corresponding parts and can be expressed as the ratio of function to cost, called value ratio (Yoshikawa et al. 1994). On the basis of value ratio, the levels of the parts characteristics can be established. It is performed before the production stage. The motivating force behind VE is to ensure that the product achieves its basic function in a way that satisfies the customer at an acceptable cost. Consequently, VE programs are the domain of the product engineer, not the accountant. The application of VE is appropriate during the conceptual design stage of a product (Cooper and Slagmulder 1997). Since QFD is particularly useful for conceptual design of a product, the integration of QFD and VE together leads to the reduction of costs and improvements of service/product or performance (Farsi and Hakiminezhad 2012).

\section{Target costing}

Target costing (TC) process is a strategic profit planning and cost management technique in which a product, that is to be manufactured in accordance with the functionality and quality demanded by the customer and determined by market research, is sold at an estimated sale price, by determining the product cost which will provide the profitability level requested by the company (Kocsoy et al. 2008). TC is considered a strategic management accounting system. This implies that its main focus is on long-term cost management rather than short-term focus adopted by more traditional cost accounting systems (Ewert and Ernst 1999). This process begins with the definition of the product, carries through setting the target cost, finding ways to achieve and achieving the target, and then maintaining a competitive cost during the life cycle of the product (Clifton et al. 2003). The target cost is derived from the target price and is calculated by the simple equation Target Cost $=$ Target price - Target profit. Both price and profit are the independent variables in the above equation. Prices are decided by what customers are willing to pay, and profit is determined by what financial markets expect as a return from that particular industry. The dependent variable is cost, which implies that a firm has to manage its cost to meet the external constraints compelled by the product and financial markets in which it operates (Ansari et al. 2006).Target cost is simply the allowable cost of a product that yields the required rate of return. TC places customer needs at the heart of the firm's efforts to develop and deploy product strategies. Target costing views meeting or exceeding customer requirements for quality, functionality, and price as key to attain and sustain product competitiveness (Archie Lockamy and Wilbur 2000). TC uses price information in the market to determine product cost. The application of $\mathrm{TC}$ in the product design stage has the greatest cost reduction potential (Gagne and Discenza 1995). It is appropriate for designing assembly type products (Helms et al. 2005). Filomena et al. (2009) developed a model to operationalize TC by breaking down cost targets into product parts, features and common elements, focusing on creating parameters for cost control during product development.

Target costing significantly relies upon QFD and VE for its effective implementation (Gandhinathan et al. 2004). VE is an essential technique to implement TC methodology (Noda and Tanaka 1997). TC helps to develop a right product and VE shows the best way of performing it. Both VE and TC are intertwined (Al Chen et al. 2008). Sharma et al. (2006) developed a synergistic management approach, in which QFD, TC and VE techniques are utilized to facilitate cross-functional product design and development, integrating both organizational and functional aspects of the development process so as to maximize value creation. The integration of QFD, TC and VE provides a competitive cost advantage to the manufacturing companies (Rezaei et al. 2013). Jariri and Zegordi (2008b) suggested that the part planning matrix of QFD is the best choice for applying VE to obtain different levels of the part characteristics and then it is suitable to implement TC approach.

\section{Methodology}

In this paper, an attempt has been made to establish a mathematical model which integrates part planning matrix of QFD, VE and TC under multi-objective approach to optimize customer satisfaction and total cost of the product. The schematic representation of the integration model is shown in Fig. 1. In the model, as VE helps to identify potential part reductions and possible combinations of part functions to keep cost aligned with value, the VE is incorporated in the part planning matrix (PPM) of QFD for obtaining various levels of parts characteristics. Correlations among the parts characteristics and interrelationship between the design requirements and the parts characteristics of the PPM are considered in the establishment of a mathematical model. In accordance with the priorities of the customer needs, the priority ratings of the design requirements are obtained in HOQ. The prioritized design requirements are carried in the PPM of QFD to 


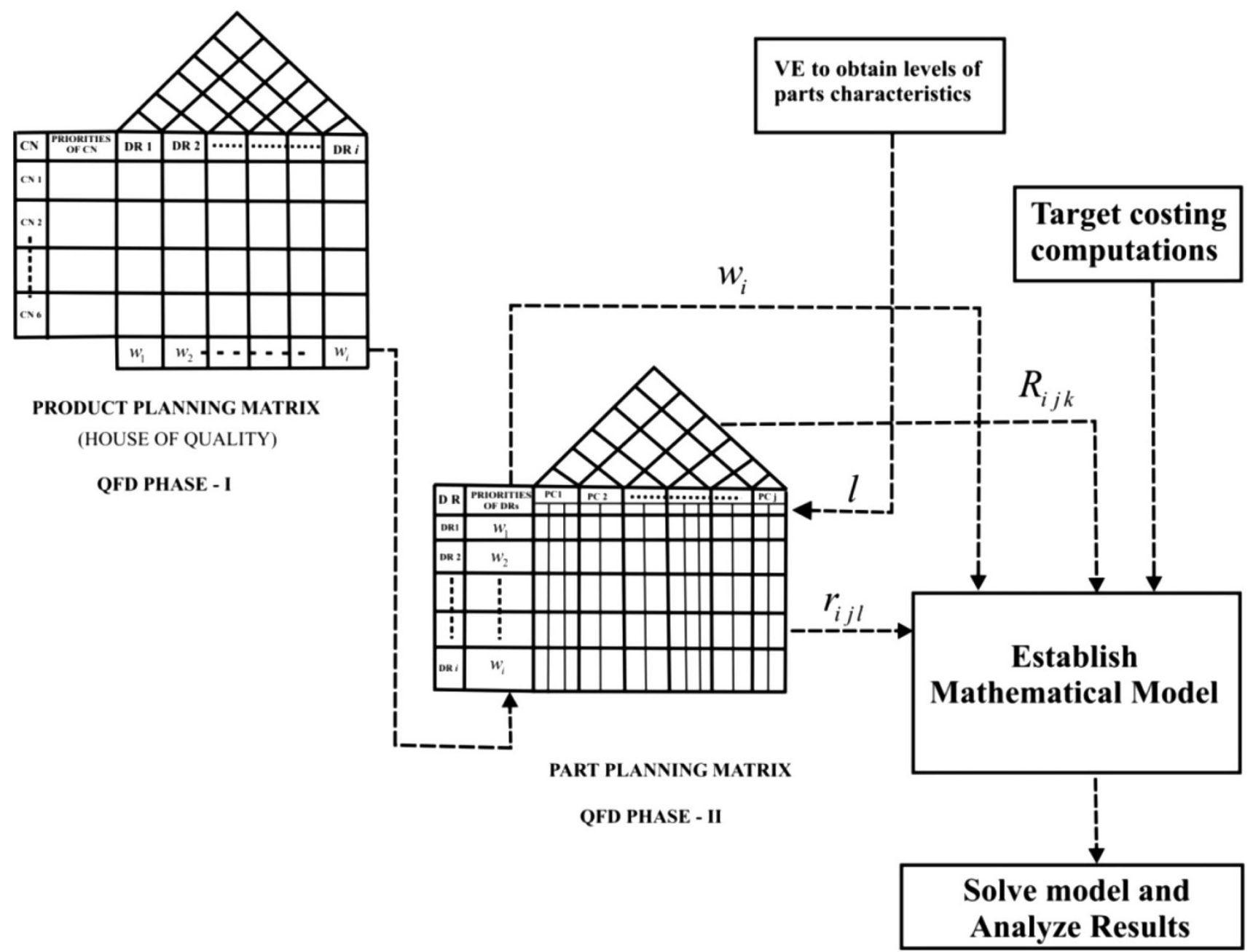

Fig. 1 QFD, VE and TC integration model

deploy customer preferences. Further, the work is carried out to identify the cost of each component using VE and TC with a view to that makes up the final product cost. A mathematical model is formulated under both single- and multi-objective optimization. The model is solved under single-objective optimization to obtain the goals, which are used in multi-objective optimization through goal programming.

Formulation of mathematical model under single-

objective optimization

Under single-objective optimization, the customer satisfaction and total cost of the product are optimized individually. These non-linear programming problems (NLPP) are solved using LINGO 8.0 to obtain optimum values of customer satisfaction index and total cost of the product. The singleobjective optimization model is discussed below.

\section{Notations}

$m \quad$ Number of design requirements

$n \quad$ Number of parts characteristics

$i \quad$ Design requirement, $i=1,2, \ldots m$

$j \quad$ Part characteristic, $j=1,2, \ldots n$

$l \quad$ Level of the parts characteristic, $l=1,2,3$

$l_{j} \quad$ Level $l$ of the parts characteristic $j$

$w_{i} \quad$ Priority rating for $i$ th design requirement

$r_{i j l} \quad$ Inter-relationship values of part planning matrix

$R_{i j k} \quad$ Elements of the roof of part planning matrix

$C_{j l} \quad$ Cost of the part $j$ in level $l$

$Y_{i} \quad$ Summation effects of parts characteristics for $i$ th design requirement

$\mathrm{TC}_{j} \quad$ Target cost of the $j$ th part

$x_{j l} \quad$ Decision variable

$x_{j l} \quad 1$, if part characteristic is appropriate at the level $l$

$x_{j l} \quad 0$, otherwise 


\section{Objectives}

Maximize customer satisfaction $\left(Z_{1}\right)$

Maximize $Z_{1}=\sum_{i=1}^{m} w_{i} Y_{i}$

Minimize total cost $\left(Z_{2}\right)$

Minimize $Z_{2}=\sum_{j=1}^{n} \mathrm{TC}_{j}$

Constraints

$\sum_{l=1}^{l_{j}} C_{j l} x_{j l} \leq \mathrm{TC}_{j}$

$\sum_{l=1}^{l_{j}} x_{j l}=1 \quad \forall j$

where

$Y_{i}=\sum_{j=1}^{j=n} \sum_{l=1}^{l_{j}} r_{i j l}\left(x_{j l}\right)+\sum_{j=1}^{n-1} \sum_{k=j+1}^{n} \sum_{l=1}^{l_{j}} \sum_{u=1}^{l_{k}} R_{i j k}\left(x_{j l}\right)\left(x_{k u}\right)$

$x_{j l} \in\{0,1\}$

The Eqs. (1) and (2) are the objective functions, maximize customer satisfaction and minimize total cost of the product, respectively. The first term of the fifth equation reflects the impact of the choice of design requirements and the second term indicates the impact of correlation of parts characteristics of the part planning matrix (roof matrix). The inter-relationship values $\left(r_{i j l}\right)$ represent the relationship between each design requirement $(i)$ and part characteristic $(j)$ at each level $(l)$. The intensity of the correlation between the parts characteristics $j$ and $k$ for the $i$ th design requirement is represented by $R_{i j k}$.

Formulation of mathematical model

under multi-objective optimization

Multi-objective optimization is the process of simultaneously optimizing two or more conflicting objectives subject to certain constraints. A decision situation is generally characterized by multiple objectives. Some of these objectives may be complementary, while others may be conflicting in nature. Goal programming allows the decision maker to specify a target or aspiration level for each objective function. A preferred solution is defined as the one that minimizes the sum of the deviations from the prescribed set of aspiration levels.

\section{Goal programming}

Goal programming was originally introduced by Charnes and Cooper in early 1961 for a linear model. This approach allows the simultaneous solution of a system of complex objectives (Belmokaddem et al. 2009). GP is a practical and robust tool for use in multi-objective mathematical programming (Ignizio 1983). The principal concept for linear GP is to the original multiple objectives into specific numeric goal for each objective. The objective function is then formulated and a solution is sought which minimizes the sum of deviations from their respective goal. The main idea in GP is to find solutions which attain a predefined target for one or more objective functions (Deb 2001). It attempts to combine the logic of optimization in mathematical programming with the decision maker's desire to satisfy several goals (Delice and Gungor 2011). GP is a suitable tool to assist the QFD planning effort (Tu et al. 2010). Karsak et al. (2002) employed a combined analytic network process (ANP) and zero-one goal programming (ZOGP) approach to incorporate the customer needs and the product technical requirements systematically into the product design phase in QFD. Wang and Ma (2007) adopted ZOGP with ANP to obtain optimum set of product quality characteristics. They presented a case study to show the effectiveness of the methodology for enhancing product design quality.

The formulation of a simple goal programming problem is given by

Min. $v(d)=\sum_{i=1}^{k}\left(d_{i}^{-}+d_{i}^{+}\right)$

Subject to $Z_{i}(x)+d_{i}^{-}-d_{i}^{+}=b_{i} ; \quad i=1,2, \ldots k$

$x, d_{i}^{-}, d_{i}^{+} \geq 0$

where $b_{i}=$ the target for goal $i, d_{i}^{-}$is the underachievement of goal $i ; d_{i}^{+}$is the overachievement of goal $i$; and $v(d)$ is the function of deviational variables known as achievement function

Goal programming is used in this present work to optimize both customer satisfaction and cost of the product simultaneously with a view to develop a product that satisfies both the objectives. The maximum customer satisfaction and minimum total cost of the product are assumed as goals in the model. GP minimizes the deviations from the target values. The original objectives are expressed as a linear equation with target values and two auxiliary variables. Negative deviation $\left(d^{-}\right)$and positive deviation $\left(d^{+}\right)$are two auxiliary variables representing 
underachievement of the target value and overachievement of the target value, respectively (Ozcan and Toklu 2009).

The GP approach of the mathematical model for the present work is given below.

Minimize $v(d)=d_{1}^{-}+d_{2}^{+}$

Subject to goal constraints

$$
\begin{aligned}
& \sum_{i=1}^{i=m} w_{i} Y_{i}+d_{1}^{-}+d_{1}^{+}=W \\
& \begin{aligned}
\sum_{j=1}^{j=n} \mathrm{TC}_{j}+d_{2}^{-}-d_{2}^{+} & =S \\
\sum_{l=1}^{l_{j}} C_{j l} x_{j l}+d_{c}^{-}-d_{c}^{+} & =\mathrm{TC}_{j} ; j=3,4, \ldots n ; c \\
& =3,4, \ldots 11
\end{aligned}
\end{aligned}
$$

where $d_{c}^{-}, d_{c}^{+}$are the deviation variables of $g$ th goal and

$Y_{i}=\sum_{j=1}^{j=n} \sum_{l=1}^{l_{j}} r_{i j l}\left(x_{j l}\right)+\sum_{j=1}^{n-1} \sum_{k=j+1}^{n} \sum_{l=1}^{l_{j}} \sum_{u=1}^{l_{k}} R_{i j k}\left(x_{j l}\right)\left(x_{k u}\right)$

$W \quad=$ goal value of customer satisfaction index

$S \quad=$ goal value of total cost of the product

$\mathrm{TC}_{j}=$ target cost of part $j$

Subject to hard constraint $\sum_{l=1}^{l_{j}} x_{j l}=1$

The objective function shown in Eq. (7) indicates the sum of the minimization of the underachievement $\left(d_{1}^{-}\right)$of customer satisfaction and overachievement $\left(d_{2}^{+}\right)$of the cost of the product. The Eqs. (8.1)-(8.3) represent goal constraints of customer satisfaction, total cost of the product and target cost of each part. Further $W, S$ and $\mathrm{TC}_{j}$ indicate the goal values corresponding to customer satisfaction, total cost of the product and target cost of each part. The equality constraint shown in Eq. (9) indicates the consideration of only one level for the given part characteristic in product design.

Table 1 Customer needs and

\section{Illustrative example}

Domestic refrigerator is considered as an example product to demonstrate the proposed model. To obtain the customer expectations in a domestic refrigerator, personal interviews with the customers, market surveys, and brain storming sessions with the targeted customers were conducted. After the comprehensive discussions and then by performing factor analysis, six basic customer needs are identified and conjoint analysis has been carried out to obtain their priority ratings, which are shown in Table 1 (Durga Prasad et al. 2010). Then the experts of the design team established seven design requirements which are shown in Table 2.

The first phase of QFD is the product planning in which house of quality (HOQ) is established. The outcome of the $\mathrm{HOQ}$ is the priorities of the design requirements, which are the input to the second phase of QFD. The combination of QFD and analytic network process (ANP) helps to provide most satisfying design for customers (Soota et al. 2011). The following QFD-ANP procedure (Venkata Subbaiah et al. 2011) is employed to obtain the priority ratings of the design requirements.

Step 1: Establish the matrix $\left(W_{1}\right)$ which shows the degree of relative importance of the DRs with respect to each $\mathrm{CN}$

The matrix $W_{1}$ is shown in Table 3 is obtained by preparing pair-wise comparisons between the DRs in respect of each CN. Saaty scale (Bayazit 2006) is adopted while preparing the pair-wise comparisons.

Step 2: Establish the inner dependence matrix $\left(W_{2}\right)$ of the CNs with respect to each $\mathrm{CN}$

With the help of pair-wise comparisons, the inner dependencies among the customer needs are calculated by analyzing the impact of each customer need on other

Table 2 List of design requirements

Design requirements (DRs)

DR-1: Enhancing compressor performance (ECOMP)

DR-2: Enhancing condenser performance (ECONP)

DR-3: Enhancing evaporator performance (EEP)

DR-4: Use good thermal insulation material (UGTIM)

DR-5: Quick response to trouble shooting (QRTS)

DR-6: Effective refrigerator controls (ERC)

DR-7: Optimum design of refrigerator compartments (ODRC) their priority ratings

\begin{tabular}{lllllll}
\hline $\begin{array}{l}\text { Customer } \\
\text { needs }(\mathrm{CNs})\end{array}$ & $\begin{array}{l}\text { Service } \\
\text { reliability } \\
(\mathrm{SR})\end{array}$ & $\begin{array}{l}\text { Preservation } \\
(\mathrm{PRE})\end{array}$ & $\begin{array}{l}\text { Refrigeration } \\
\text { effect (RE) }\end{array}$ & $\begin{array}{l}\text { Storage } \\
\text { volume (SV) }\end{array}$ & $\begin{array}{l}\text { Price } \\
(\mathrm{PR})\end{array}$ & $\begin{array}{l}\text { Energy } \\
\text { consumption } \\
(\mathrm{EC})\end{array}$ \\
\hline $\begin{array}{c}\text { Priority } \\
\text { ratings }(W)\end{array}$ & 17.47 & 14.579 & 11.459 & 11.482 & 13.699 & 31.311 \\
\hline
\end{tabular}


Table 3 Degree of relative importance of the DRs with respect to CNs $\left(W_{1}\right)$

\begin{tabular}{lllllll}
\hline DR & CN & & & & & \\
\cline { 2 - 7 } & SR & PRE & RE & SV & PR & EC \\
\hline ECOMP & 0.1568 & 0.1568 & 0.3700 & 0.1568 & 0.3745 & 0.2450 \\
ECONP & 0.0983 & 0.0607 & 0.1578 & 0.0607 & 0.2450 & 0.1568 \\
EEP & 0.0607 & 0.0983 & 0.2462 & 0.0983 & 0.1568 & 0.0983 \\
UGTIM & 0.0388 & 0.2450 & 0.0989 & 0.2450 & 0.0607 & 0.3745 \\
QRTS & 0.3745 & 0.0260 & 0.0262 & 0.0260 & 0.0260 & 0.0260 \\
ERC & 0.2450 & 0.0388 & 0.0611 & 0.0388 & 0.0388 & 0.0607 \\
ODRC & 0.0260 & 0.3745 & 0.0398 & 0.3745 & 0.0983 & 0.0388 \\
\hline
\end{tabular}

customer need. The inner dependence matrix of the customer needs is shown in Table 4.

Step 3: Establish inner dependence matrix $\left(W_{3}\right)$ of the DRs with respect to each DR

The inner dependencies among the design requirements are obtained through analyzing the impact of each design requirement on other design requirement by establishing pair-wise comparisons. The inner dependence matrix of the design requirements is shown in Table 5.

Step 4: Determine the interdependent priority matrix $\left(W_{C}\right)$ of the customer needs using

$W_{C}=W_{2} \times W$

where $W=$ the matrix of priority ratings of customer needs
Table 4 The inner dependence matrix of the customer needs $\left(W_{2}\right)$

\begin{tabular}{lllllll}
\hline CN & CN & & & & & \\
\cline { 2 - 6 } & SR & PRE & RE & SV & PR & EC \\
\hline SR & 0.3975 & 0.3277 & 0.0642 & 0.1346 & 0.3247 & 0.3963 \\
PRE & 0.1527 & 0.1080 & 0.2541 & 0.2501 & 0.1176 & 0.1322 \\
RE & 0.2565 & 0.2486 & 0.1969 & 0.2358 & 0.1555 & 0.1131 \\
SV & 0.1360 & 0.2007 & 0.0376 & 0.1559 & 0.2768 & 0.2206 \\
PR & 0.0280 & 0.0340 & 0.2191 & 0.0399 & 0.0607 & 0.0413 \\
EC & 0.0727 & 0.0811 & 0.2281 & 0.1838 & 0.0647 & 0.0965 \\
\hline
\end{tabular}

Step 6: Determine the overall priorities of the design requirements $(w)$ using $w=W_{A} \times W_{C}$

$w=\left[\begin{array}{r}\text { ECOMP } \\ \text { ECONP } \\ \text { EEP } \\ \text { UGTIM } \\ \text { QRTS } \\ \text { ERC } \\ \text { ODRC }\end{array}\right]=\left[\begin{array}{l}27.31 \\ 18.55 \\ 14.45 \\ 11.34 \\ 7.010 \\ 5.940 \\ 15.40\end{array}\right]$

These priority ratings of the design requirements (w) are carried in the establishment of mathematical model. After the first phase of QFD, the second phase of QFD is initiated by identifying the parts characteristics.

$W_{C}=\left[\begin{array}{llllll}0.397491 & 0.327707 & 0.064182 & 0.134597 & 0.324716 & 0.276778 \\ 0.152674 & 0.107983 & 0.254061 & 0.250076 & 0.117574 & 0.132215 \\ 0.256510 & 0.248594 & 0.196918 & 0.235793 & 0.155520 & 0.113110 \\ 0.136012 & 0.200706 & 0.037593 & 0.155874 & 0.276778 & 0.081051 \\ 0.028048 & 0.033959 & 0.219138 & 0.039852 & 0.060665 & 0.041319 \\ 0.072669 & 0.081051 & 0.228108 & 0.183808 & 0.064747 & 0.072669\end{array}\right] \times\left[\begin{array}{l}17.470 \\ 14.579 \\ 11.459 \\ 11.482 \\ 13.699 \\ 31.311\end{array}\right]=\left[\begin{array}{l}27.112 \\ 15.775 \\ 18.741 \\ 13.852 \\ 6.0785 \\ 10.338\end{array}\right]$

Step 5: Determine the interdependent priority matrix $\left(W_{A}\right)$ of the design requirements using

$W_{A}=W_{3} \times W_{1}$
The experts of the design team used VE approach to identify the parts characteristics and their levels to meet the design requirements. In this approach, brain storming sessions are conducted among the design team members. The parts of the refrigerator are identified and the

$$
W_{A}=\left[\begin{array}{llllll}
0.312710 & 0.233701 & 0.315315 & 0.233701 & 0.296413 & 0.306985 \\
0.211446 & 0.173990 & 0.190051 & 0.173990 & 0.205208 & 0.202843 \\
0.187223 & 0.058957 & 0.180141 & 0.186106 & 0.176183 & 0.058957 \\
0.113487 & 0.117523 & 0.123078 & 0.117523 & 0.115266 & 0.121478 \\
0.081099 & 0.063105 & 0.076713 & 0.063105 & 0.070516 & 0.077345 \\
0.058957 & 0.065610 & 0.060438 & 0.065610 & 0.059888 & 0.058957 \\
0.166692 & 0.058957 & 0.315315 & 0.065610 & 0.183364 & 0.167648
\end{array}\right]
$$


Table 5 The inner dependence matrix of the design requirements $\left(W_{3}\right)$

\begin{tabular}{llllllll}
\hline DR & DR & \multicolumn{7}{l}{} & & & & \\
\cline { 2 - 7 } & ECOMP & ECONP & EEP & UGTIM & QRTS & ERC & ODRC \\
\hline ECOMP & 0.3420 & 0.2727 & 0.3389 & 0.3088 & 0.3131 & 0.3273 & 0.0901 \\
ECONP & 0.1638 & 0.3421 & 0.1299 & 0.1927 & 0.2155 & 0.2137 & 0.1433 \\
EEP & 0.1949 & 0.1356 & 0.1779 & 0.2024 & 0.2136 & 0.1631 & 0.1826 \\
UGTIM & 0.1078 & 0.0952 & 0.1647 & 0.1325 & 0.1028 & 0.1262 & 0.1031 \\
QRTS & 0.0882 & 0.0448 & 0.0791 & 0.0852 & 0.0839 & 0.0918 & 0.0325 \\
ERC & 0.0624 & 0.0474 & 0.0652 & 0.0586 & 0.0495 & 0.0600 & 0.0763 \\
ODRC & 0.1838 & 0.0622 & 0.1870 & 0.1626 & 0.1645 & 0.1608 & 0.5046 \\
\hline
\end{tabular}

function of each part is evaluated and then classified into three levels on the basis of value index. Finally, the principal parts along with their levels are established and are shown in Table 6.

In this study, same correlation between the parts characteristics for all the design requirements is assumed.

To assign the relationship values while establishing the parts planning matrix by the design team, a three-point ordinal scale 1-3-9 (1, weak; 3, medium; and 9, strong) (Franceschini and Rupil 1999) is employed. For instance, the relation between DR-1(Enhancing compressor performance) and PC-1 at the level I (1/3 hp Hermetic compressor) is strong and hence value 9 is assigned in the corresponding cell of the matrix. As there is a medium relation between DR-1 and the PC-1 at the level II (1/6 hp Hermetic compressor), the value 3 is assigned. The relation between the DR-1 and the PC- 1 at the level III (1/8 hp Hermetic compressor) is weak and hence value 1 is assigned in the corresponding cell of the matrix. Similarly, the inter-relationship matrix is completely filled by the appropriate relationship values. The intensity of the correlation among the parts characteristics is also quantified using the same three-point ordinal scale. For example, the correlation between PC-1 (Hermetic compressor) and PC-2 (Wire on tube condenser) in respect of enhancing the compressor performance (DR-1) is strong and the correlation value 9 is assigned to the corresponding cell in the roof of the matrix. In the same manner, the roof matrix is prepared. The completely filled parts planning matrix is shown in Fig. 2.

\section{Mathematical model}

Under single-objective optimization, the objectives such as customer satisfaction and total cost of the product are optimized individually subject to constraints (3), (4) and (6) mentioned in the "Formulation of mathematical model under single objective optimization" using LINGO 8.0 solver. While optimizing customer satisfaction, the customer satisfaction index is 27,579 , whereas optimizing the total cost of the product yields total cost of the refrigerator is Rs. 6,203. If the former criterion of optimization is used to manufacture a refrigerator, the cost of the refrigerator is Rs. 9,616. This cost may not be affordable to the customer even though it possesses high customer satisfaction index. The refrigerator is manufactured by considering the criterion of cost minimization, the cost of the refrigerator is decreased to Rs. 6,203. But customer satisfaction index is drastically reduced to 13 , 329 and it indicates that the refrigerator cannot give complete satisfaction to the customers. In view of attaining both the objectives, the following multi-objective model is developed using GP.

In GP approach, the designer has to set a goal to be attained for each objective and a measure of deviations of the objective functions from their respective goals is minimized. The goal values considered in this model are 27,579 and Rs. 6,203 for customer satisfaction index and total cost of the refrigerator respectively.

Minimize $\quad v(d)=d_{1}^{-}+d_{2}^{+}+d_{3}^{+}+d_{4}^{+} \quad+d_{5}^{+}+d_{6}^{+}+$ $d_{7}^{+}+d_{8}^{+}+d_{9}^{+}+d_{10}^{+}+d_{11}^{+}$

Subject to goal constraints

$$
\begin{aligned}
& 27.31\left(Y_{1}\right)+18.55\left(Y_{2}\right)+14.45\left(Y_{3}\right)+11.34\left(Y_{4}\right) \\
& +7.01\left(Y_{5}\right)+5.94\left(Y_{6}\right)+15.4\left(Y_{7}\right)-d_{1}^{+}+d_{1}^{-}=27,579 \\
& \mathrm{TC}_{1}+\mathrm{TC}_{2}+\mathrm{TC}_{3}+\mathrm{TC}_{4}+\mathrm{TC}_{5}+\mathrm{TC}_{6}+\mathrm{TC}_{7}+\mathrm{TC}_{8} \\
& +\mathrm{TC}_{9}-d_{2}^{+}+d_{2}^{-}=6,203 \\
& 2,800\left(x_{11}\right)+2,350\left(x_{12}\right)+2,000\left(x_{13}\right)-d_{3}^{+}+d_{3}^{-}=\mathrm{TC}_{1} \\
& 700\left(x_{21}\right)+500\left(x_{22}\right)+450\left(x_{23}\right)-d_{4}^{+}+d_{4}^{-}=\mathrm{TC}_{2} \\
& 1,500\left(x_{31}\right)+1,200\left(x_{32}\right)+1,000\left(x_{33}\right)-d_{5}^{+}+d_{5}^{-}=\mathrm{TC}_{3} \\
& 66\left(x_{41}\right)+62\left(x_{42}\right)+48\left(x_{43}\right)-d_{6}^{+}+d_{6}^{-}=\mathrm{TC}_{4} \\
& 250\left(x_{51}\right)+180\left(x_{52}\right)-d_{7}^{+}+d_{7}^{-}=\mathrm{TC}_{5} \\
& 900\left(x_{61}\right)+600\left(x_{62}\right)-d_{8}^{+}+d_{8}^{-}=\mathrm{TC}_{6} \\
& 2,000\left(x_{71}\right)+1,000\left(x_{72}\right)-d_{9}^{+}+d_{9}^{-}=\mathrm{TC}_{7} \\
& 500\left(x_{81}\right)+325\left(x_{82}\right)-d_{10}^{+}+d_{10}^{-}=\mathrm{TC}_{8} \\
& 900\left(x_{91}\right)+700\left(x_{92}\right)+600\left(x_{93}\right)-d_{11}^{+}+d_{11}^{-}=\mathrm{TC}_{9}
\end{aligned}
$$




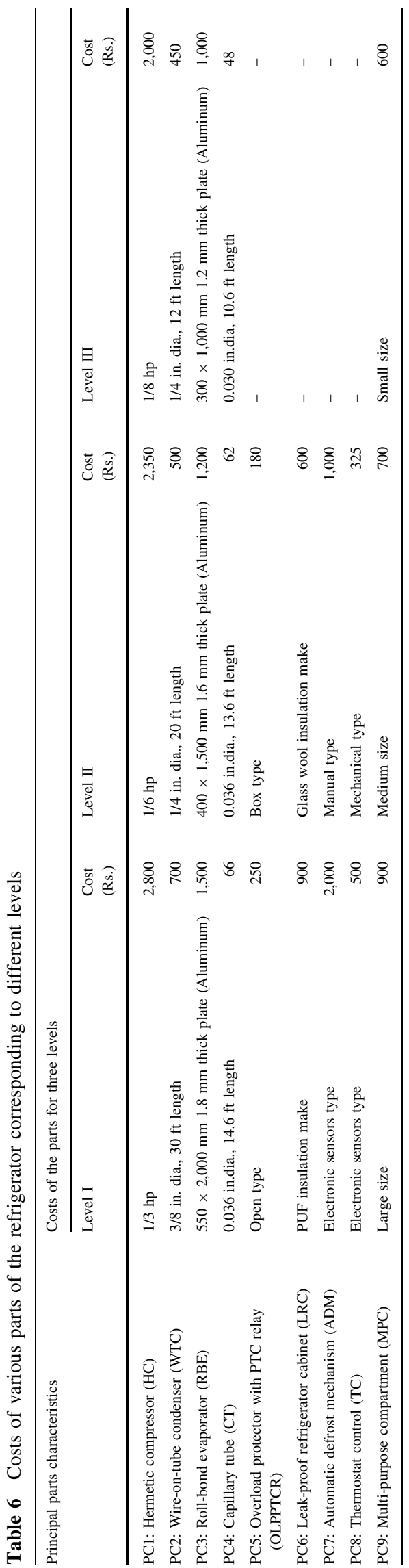

$$
\begin{aligned}
& x_{11}+x_{12}+x_{13}=1 \\
& x_{21}+x_{22}+x_{23}=1 \\
& x_{31}+x_{32}+x_{33}=1 \\
& x_{41}+x_{42}+x_{43}=1 \\
& x_{51}+x_{52}=1 \\
& x_{61}+x_{62}=1 \\
& x_{71}+x_{72}=1 \\
& x_{81}+x_{82}=1 \\
& x_{91}+x_{92}+x_{93}=1 \\
& Y_{i}=\sum_{j=1}^{j=n} \sum_{l=1}^{l_{j}} r_{i j l}\left(x_{j l}\right)+\sum_{j=1}^{n-1} \sum_{k=j+1}^{n} \sum_{l=1}^{l_{j}} \sum_{u=1}^{l_{k}} R_{i j k}\left(x_{j l}\right)\left(x_{k u}\right)
\end{aligned}
$$

\section{Results and discussion}

Mathematical model discussed in the previous section is solved using LINGO 8.0 solver and the results are shown in Table 7. The comparison of the results for singleobjective optimization and multi-objective optimization approaches is presented in this table. Maximum customer satisfaction and minimum total cost of the product are the objectives considered in case (1) and case (2), respectively, under single-objective approach. In case (3), both these objectives are considered simultaneously under multi-objective approach. The case (1) yields customer satisfaction index as 27,579 and the total cost of the refrigerator is Rs. 9,616. The customer satisfaction index and total cost are reduced to 13,329 and Rs. 6,203, respectively, in case (2). But a customer is expected to purchase a product at minimum cost and to get more satisfaction from the product simultaneously. Therefore, the design team has to concentrate on trade-off the objectives. Goal programming technique is employed in case (3) to attain both the objectives. In this case, the customer satisfaction index and the cost of the refrigerator are 23,642 and Rs. 6,917, respectively. From the Table 7, as compared to the case (1), the case (3) yields $28.06 \%$ of cost reduction in consequent to a decrease of $14.27 \%$ of customer satisfaction. In comparison with case (2), the customer satisfaction is drastically increased by $77.37 \%$ in the case (3) for the increase of $11.5 \%$ of the cost of the refrigerator.

Therefore, the refrigerator is manufactured by assembling the principle parts such as hermetic compressor, wire-on-tube condenser, roll-bond evaporator, capillary tube, overload protector with relay, refrigerator cabinet, automatic defrost mechanism, and thermostat control and multi-purpose compartment should be selected in level II to achieve both the objectives simultaneously. 
Fig. 2 Part planning matrix of QFD
Table 7 Comparison of singleobjective and multi-objective approaches

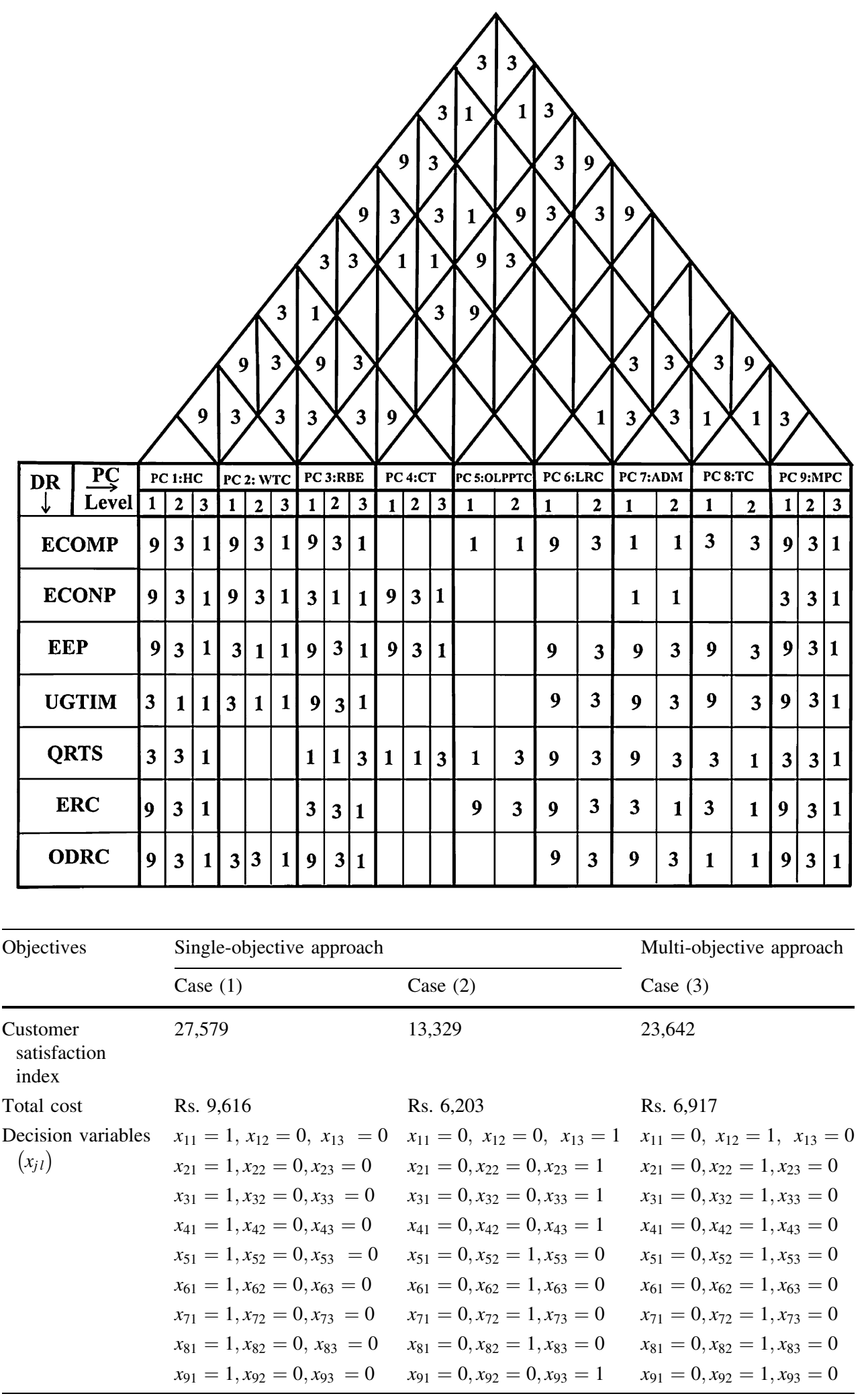

Managerial implications of the study

From the management perspective, the research paves the way for the managers to develop a product with trade-off between customer satisfaction and total cost of the product. The methodology proposed in this paper can be utilized to make critical managerial decisions such as the selection of the parts characteristics of a product in accordance with the customer needs, 
estimation of the target cost of each part and categorization of the parts into different levels. Furthermore, it is possible for the managers to take effective decision on selection of suppliers for the parts in the product design stage itself.

\section{Conclusions}

The proposed multi-objective optimization frame work improves product development and intends to balance customer satisfaction, cost and functionality of the product. In the QFD process, the actual product design is carried in the second phase. Therefore, part planning matrix is considered in the model with a view to consider the parts characteristics in accordance with the customer views. Target costing is a cost management tool that can be used at design level for cost determination and management. The target costing along with value engineering is appropriate to control and manage the cost of the product during the conceptual design stage. The multi-objective approach adopted in the proposed methodology guides the team to ensure a product with minimum cost and give more satisfaction to the customer. Goal programming is a simple and well-known method for solving multi-objective models. In this work, GP model is formulated to achieve the objectives of maximizing customer satisfaction and minimizing cost. The proposed model can also be used in process industries by considering the third phase (process planning matrix) of QFD.

Open Access This article is distributed under the terms of the Creative Commons Attribution License which permits any use, distribution, and reproduction in any medium, provided the original author(s) and the source are credited.

\section{References}

Al Chen YS, Zuckerman GJ, Zering K (2008) Applying target costing in the development of marketable and environmentally friendly products from swine waste. Eng Econ 53(2):156-170

Ansari S, Bell J, Okano H (2006) Target costing: uncharted research territory. Handbook Man Acc Res 2:507-530

Archie Lockamy III, Wilbur I (2000) Target Costing for supply chain management: criteria and selection. Ind Man Data Syst $100(5): 210-218$

Bayazit O (2006) Use of analytic network process in vendor selection decisions. Benchmarking 13(5):566-579

Belmokaddem M, Mekidiche M, Sahed A (2009) Application of a fuzzy goal programming approach with different importance and priorities to aggregate production planning. J Appl Quant Meth 4(3):317-331

Bode J, Fung RYK (1998) Cost engineering with quality function deployment. Comput Ind Eng 35(3-4):587-590

Clifton MB, Bird HMB, Albano, Townsend WP (2003) Target costing: market driven product design. ESE Group, Princeton

Cooper R, Slagmulder R (1997) Target costing and value engineering. Productivity Press, Portland

Deb K (2001) Multi-objective optimization using evolutionary algorithms. Wiley, Chichester
Dekker H, Smidt P (2003) A survey of the adoption and use of target costing in Dutch firms. Int J Prod Econ 84(3):293-305

Delice EK, Gungor Z (2011) A mixed integer goal programming model for discrete values of design requirements in QFD. Int $\mathbf{J}$ Prod Res 49(10):2941-2957

Durga Prasad KG, Venkata Subbaiah K, Narayana Rao K, Sastry CVRS (2010) Prioritization of customer needs in house of quality using conjoint analysis. Intern J Qual Res 4(2):145-154

Ernst R, Kamarad B (2000) Evaluation of supply chain structures through modularization and postponement. Eur J Oper Res 124(3):495-510

Eversheim W, Neuhausen J, Sesterhenn M (1998) Design to cost for production systems. CIRP Ann Manuf Technol 47(1):357-360

Ewert R, Ernst C (1999) Target costing, co-ordination and strategic cost management. Europ Acc Rev 8(1):23-49

Farsi JY, Hakiminezhad N (2012) The integration of QFD technique, value engineering and design for manufacture and assembly (DFMA) during the product design stage. Adv Environ Biol 6(7):2096-2104

Filomena TP, Neto FJK, Duffey MR (2009) Target costing operationalization during product development: model and application. Int J Prod Econ 118(2):398-409

Fogliatto FS, Da Silveira GJC, Royer R (2003) Flexibility-driven index for measuring mass customization feasibility on industrialized products. Int J Prod Res 41(8):1811-1829

Franceschini F, Rupil A (1999) Rating scales and prioritization in QFD. Intern J Qual Rel Man 16(1):85-97

Gagne ML, Discenza R (1995) Target costing. J Bus Ind Market 10(1):16-22

Gandhinathan R, Raviswaran N, Suthakar M (2004) QFD-and VEenabled target costing: a fuzzy approach. Intern J Qual Rel Man 21(9): 1003-1011

Gosh P, Roy TK (2013) A goal geometric programming problem with logarithmic deviational variables and its applications on two industrial problems. J Ind Eng Intern 9(5):1-9

Hassan Alaa, Siadat Ali, Dantan JY, Martin P (2009) A quality/costbased improvement approach for conceptual process planning. Intern J Man Sci Eng Man 4(3):188-197

Helms MM, Ettkin LP, Baxter JT, Gordon MW (2005) Managerial implications of target costing. Compet Rev 15(1):49-56

Ibusuki U, Kaminski PC (2007) Product development process with focus on value engineering and target-costing: a case study in an automotive company. Int J Prod Econ 105(2):459-474

Ignizio JP (1983) Generalized goal programming: an over view. Comput Oper Res 10(4):277-289

Iranmanesh SH, Thomson V, Salimi MH (2005) Design parameter estimation using a modified QFD method to improve customer perception. Concur Eng Res Appl 13(1):57-67

Jariri F, Zegordi SH (2008a) Quality function deployment, value engineering and target costing, an integrated framework in design cost management: a mathematical programming approach. Scientia Iranica 15(3):405-411

Jariri F, Zegordi SH (2008b) Quality function deployment planning for platform design. Int J Adv Man Technol 36(5-6):419-430

Jiang JC, Shiu Ming-Li, Mao-Hsiung Tu (2007) DFX and DFSS: how QFD integrates them. Qual Progr 40(10):45-51

Karsak EE, Sozer S, Alptekin SE (2002) Product planning in quality function deployment using a combined analytic network process and goal programming approach. Comput Ind Eng 44(1):171-190

Kocsoy M, Gurdal K, Karabayir ME (2008) Target costing in Turkish manufacturing enterprises. Europ J Soc Sci 7(2):92-105

Mendoza N, Ahuett H, Molina A (2003) Case studies in the integration of QFD, VE and DFMA during the product design stage In: Proceedings of the 9th International Conference of Concurrent Engineering, Espoo, Finland 
Noda K, Tanaka M (1997) Target cost management for profit engineering system based on VE in Japanese automotive parts manufacturing In: SAVE International Conference Proceedings, pp 211-220

Ozcan U, Toklu B (2009) Multiple-criteria decision-making in twosided assembly line balancing: a goal programming and a fuzzy goal programming models. Comput Oper Res 36(6):1955-1965

Rezaei DH, Salehzadeh R, Attarpour M, Baloei JH (2013) Customer focused product design using integrated model of target costing, quality function deployment and value engineering. J Prod Oper Man 3(2):77-88

Ross HM, Mazur Glenn (2009) Cost-cutting QFD: How to reduce non-value added costs in goods and services, Transactions from the 21st Symposium on Quality function deployment. Savannah, Georgia, pp 47-60

Sharma J (2012) A cross-disciplinary approach to product development and design through quality function deployment, target costing and value engineering. Intern $\mathrm{J}$ Prod Qual Man 9(3):309-331

Sharma JR, Sharma DK, Rawani AM (2006) Quality driven product development. Man Eng (IET) 85(3):38-41

Soota T, Singh H, Mishra RC (2011) Fostering product development using combination of QFD and ANP: a case study. J Ind Eng Intern 7(14):29-40

Takai S, Ishii K (2006) Integrating target costing into perceptionbased concept evaluation of complex and large-scale systems using simultaneously decomposed QFD. J Mech Des 128(6):1186-1195

Tang J, Fung RYK, Xu B, Wang D (2002) A new approach to quality function deployment planning with financial consideration. Comput Oper Res 29(11):1447-1463

Tsai YT, Chang YM (2004) Function-based cost estimation integrating quality function deployment to support system design. Int $\mathrm{J}$ Adv Man Technol 23(7-8):514-522

Tu CS, Chang CT, Chen KK, Lu HA (2010) Applying an AHP-QFD conceptual model and zero-one goal programming to requirement-based site selection for an airport cargo logistics center. Int J Inf Man Sci 21(4):407-430

Venkata Subbaiah K, Durga Prasad KG, Narayana Rao K (2011) Customer-driven product planning using conjoint analysis and QFD-ANP methodology. Intern J Prod Qual Man 7(3):374-394

Wang MQ, Ma YS (2007) A systematic method for mapping customer requirements to quality characteristics in product lifecycle. Int J Simul Proc Model 3(4):229-237

Yoshikawa T, Innes J, Mitchell F (1994) Applying functional cost analysis in a manufacturing environment. Int $\mathrm{J}$ Prod Econ 36(1):53-64

Zeng Y, Gu P (1999) A science-based approach to product design theory part II: formulation of design requirements and products. Robot Comp Integr Man 15(4):341-352

Zengin Y, Ada E (2010) Cost management through product design: target costing approach. Int J Prod Res 48(19):5593-5611 